\title{
Sobre infância, saúde e gênero: discursos biomédicos na mídia impressa de 1990
}

\section{On childhood, health and gender: biomedical discourses in the printed media of 1990}

\author{
Heloísa Derkoski Dalla Nora ${ }^{1}$ \\ Eliane Cadoná ${ }^{2}$
}

Resumo: Apresentamos, aqui, a análise das sessões saúde do jornal Zero Hora do ano de 1990 - ano de publicação das leis no 8.080/90 e no 13.257/90 -, buscando evidenciar sentidos de Gênero, Saúde e Infância ali veiculados. Utilizamos como instrumentos teórico-metodológicos o Construcionismo Social e as Teorias de Gênero Pós-Estruturalistas, com foco na Análise de Discurso. A partir de eixos temáticos, refletimos sobre as (des)articulações discursivas veiculadas no jornal com os princípios do ECA e do SUS, no intuito de compreender os sentidos dados às temáticas evidenciadas naquele cenário.

Palavras-chave: infância; mídia; gênero; saúde; políticas públicas.

Abstract: Here, we present, an analysis of the health sessions of the Zero Hora newspaper of the year 1990 - year of publication of laws 8.080/90 and 13.257/90 - seeking what meanings of Gender, Health and Childhood are communicated there. We use as theoretical-methodological instruments the Social Constructionism and post-structural Gender theories, focusing on Discourse Analysis. From thematic axes, we reflect on how the discursive (dis) articulations conveyed in the newspaper with principles of ECA and SUS, in intention to understand the meanings of some discussions evidenced by that scenario.

Keywords: childhood; media; gender; health; public policies.

1 Universidade Regional Integrada do Alto Uruguai e das Missões (URI). Erechim, RS, Brasil. https://0000-0002-5980-6119. E-mail: heloisadallanora@yahoo.com.br

2 Universidade Regional Integrada do Alto Uruguai e das Missões (URI). Erechim, RS, Brasil. https://orcid.org/0000-0003-3988-9786. E-mail: cadonaeliane@gmail.com 


\section{Introdução e aportes teóricos}

Objetivamos, com esta pesquisa, evidenciar os possíveis processos de subjetivação envolvidos na construção de conceitos de Infância, Gênero e Saúde no ano de 1990, por intermédio da análise da Mídia Impressa. Um dos mais influentes meios de comunicação da Modernidade, o jornal ainda ocupa lugar nas discussões sobre produção de subjetividade e na maneira como nossa sociedade se organiza e, consequentemente, produz sentidos no cotidiano (THOMPSON, 2014; SPINK; SPINK, 2006).

Os primeiros passos da investigação consistiram em analisar como aconteceu a veiculação dos conceitos de Gênero, Saúde e Infância nas sessões saúde do jornal Zero Hora, do ano de 1990, até a data de publicação da Lei Federal nº 8.069 (BRASIL, 1990a), dia 13 de julho do mesmo ano, que regulamenta o Estatuto da Criança e do Adolescente (ECA). Neste mesmo ano também foram aprovadas as Leis Federais $n^{\circ}$ 8.080 e n $^{\circ} 8.142$ (BRASIL, 1990b; BRASIL, 1990c), que versam sobre os princípios e diretrizes do Sistema Único de Saúde (SUS) e controle social. Dessa forma, abordaremos aqui como eram discutidos e veiculados conceitos-chaves para o entendimento de Leis, em iminência de serem aprovadas, com visões de sujeito tão diferentes das em vigência até então.

O ano de 1990 foi importante e contraditório para o País no que diz respeito à publicação de políticas públicas e à fase de redemocratização pela qual passava. Isso porque as Leis acima referidas são aprovadas em um contexto de adoção de inúmeras políticas de Estado neoliberais. Mesmo com a mudança legislativa para um modelo democrático, a cosmovisão do liberalismo imperava não somente nas práticas de Estado, mas também na visão de sujeito da sociedade como um todo.

Souza (2016) entende que a aprovação do Estatuto da Criança e do Adolescente e das Leis Orgânicas da Saúde só foi possível devido ao processo de redemocratização que o Brasil vivia. A retomada da democracia aconteceu em um momento em que uma pequena parcela da população detinha muito mais da metade dos meios de produção. No cenário 
em questão, ocorria um reordenamento das políticas públicas, devido a uma crise socioeconômica que o País passava. A alta taxa de mortalidade infantil e a epidemia de AIDS, que acontecem na década de 1980 são resultados, também, da extrema pobreza e da falha na atenção à saúde (RODRIGUES, 1992).

Em 1988, com a aprovação da Constituição Cidadã (BRASIL, 1988) diversos direitos são concedidos aos/às cidadãos/ãs, junto à garantia da democracia e com a possibilidade de interferência do povo no poder legislativo, através das várias estratégias de controle social previstas em Lei. Concomitante a esse cenário, o presidente Fernando Collor assume, em 1990, com uma agenda neoliberal, que incluía a abertura ao mercado externo, a privatização de empresas estatais e demissões em massa (RODRIGUES, 1992). Segundo Bueno (2012), fatos indicam que alguns direitos cidadãos, como a greve, não eram respeitados, mesmo após a aprovação da nova Constituição.

Um exemplo das dificuldades causadas por essa contradição política é o fato de que, ainda em 1990, o presidente Collor vetou todos os artigos que tratavam sobre o controle social, parte da Lei que falava sobre a participação da comunidade na gestão, através dos Conselhos de Saúde. A Lei no 8.142 (BRASIL, 1990c), que inclui essas decisões, só é aprovada em dezembro desse mesmo ano. Por todos esses motivos, entendemos que 1990 é um marco no que diz respeito a políticas públicas e, por isso, deve ser alvo de pesquisas não só da área da história, mas também de outros campos que estejam dispostos a procurar nela problematizações vivenciadas na contemporaneidade.

Abordaremos aqui, também, a problematização dos sentidos de Cuidado e Família veiculados pelo jornal, procurando entender como eles se relacionam entre si e com o tema da pesquisa. Não esquecendo nossos documentos base, o ECA e o SUS, iremos nos voltar para a mídia e procurar entender como os atravessamentos de gênero ocupam espaço na produção de subjetividade (GUATTARI; ROLNIK, 1996) no que diz respeito à Família e ao Cuidado na infância. 
Como referencial teórico para discutir esse assunto escolhemos o Construcionismo Social (GERGEN, 2009; IÑIGUEZ, 2002; SPINK, 2013; SPINK, 2013) e os Estudos de Gênero de abordagem pós-estruturalista (BUTLER apud SALIH, 2013; LOURO, 2003; STREY; CADONÁ, 2012). Com essa visão de mundo, entendemos que o sujeito se constrói nas relações que estabelece e no modo como dá sentido a elas, sendo o papel da ciência investigar na história como determinados conceitos foram investidos por diversos mecanismos de produção de subjetividade. A partir dessa base epistemológica, entendemos a importância do estudo do Tempo Presente (PADRÓS, 2004), com fins de propor novos olhares para como damos sentido às nossas relações e conceituações.

Como norte da pesquisa, a fim de compreender os objetos de estudo, fazemos uso do Construcionismo Social (GERGEN, 2009; IÑIGUEZ, 2002). Essa escolha se deu por entendermos que os temas estudados aqui precisam ser vistos como construções sociais, originadas através de um longo e dialógico processo que envolve a relação dos sujeitos com o mundo, estando marcada por tempos e lugares. Dessa forma, essa teoria nos dá suporte para discutirmos a produção de subjetividade que envolve e é consequência dessa construção, tendo influência no modo como vivemos hoje e como as pessoas se relacionam consigo mesmas e com o mundo.

Um dos principais autores que escrevem sobre a construção da infância, bem como da família, é Philippe Ariès. Em suas pesquisas, ele destaca a estreita conexão entre esse processo de descoberta das crianças com o cristianismo e a arte. Através da análise das obras de arte medievais, Ariès (1981) retrata a evolução na representação da infância. Segundo Souza (2016) é indispensável que se volte na história para entender o presente, sendo que este é também fruto de uma sociedade hierarquizada, não só na esfera federal, mas também em uma perspectiva global.

Até o fim do século XIII, ainda não existia uma imagem que representasse a criança. Isso não quer dizer que essa figura estivesse ausente 
nessa época, mas que era diferente do que conhecemos hoje, pois estava estreitamente ligada ao adulto, sendo percebida como uma miniatura dele. Existe um lento processo até a diferenciação dessas fases do desenvolvimento, que foi retardado pelas condições demográficas da época, onde a taxa de mortalidade infantil era extremamente alta. É só no século XVIII que essas condições começam a mudar. Com a adoção de alguns métodos contraceptivos e uma melhora nas condições de vida, a indiferença em relação à infância começa a se transformar em uma valorização dessa etapa como algo puro. Durante esse processo, podemos citar a imagem dos anjos e do menino Jesus como contribuições para tal consequência (ARIÈS, 1981).

No cenário nacional de políticas públicas, devemos voltar à roda dos expostos, uma herança do Brasil colonial que teve fim apenas em 1950. Dispositivo que permitia o abandono das crianças para casas de misericórdias assumirem seus cuidados, a roda pode ser considerada como a primeira iniciativa de juntar o público com o privado, já que, através de uma lei, os municípios puderam se eximir da obrigação de cuidar dessas crianças, que ficaram sob a responsabilidade de tais instituições (CRUZ; HILLESHEIN; GUARESCHI, 2005).

Outro fator importante a ser destacado é a formulação do conceito de trabalho como enobrecedor. Trazida com a imigração europeia, a institucionalização desse conceito foi o começo da reserva de mão de obra, e resultou em muitas crianças e adolescentes nas ruas. Esse movimento foi considerado a causa do aumento da criminalidade e, sendo assim, com uma lógica higienista, o governo direcionou esses jovens para Casas de Correção, iniciando, dessa forma, o sequestro da subjetividade desse público, com a proposta de prevenção, visando educá-los para o trabalho. Nesse momento já é possível entender que existiu a criação de duas infâncias distintas. O primeiro Código de Menores, de 1927, reforça isso quando faz uma distinção entre os menores em situação irregular, caracterizados por abandonados, delinquentes e viciados. É nessa época que o termo menor é adotado como sinônimo de infância. Não podemos esquecer o papel que a escola exerceu como produtora de 
subjetividades docilizadas nesse cenário, já que ela incorpora discursos científicos, como os da Psicologia, no intuito de medir, testar e quantificar os/as alunos/as. É no período de 1931 a 1934 que ela se insere definitivamente nas escolas brasileiras e, através das testagens, também auxilia nesse processo, cumprindo um papel de separar os aptos dos não aptos, acentuando ainda mais essas diferenças (CRUZ; HILLESHEIN; GUARESCHI, 2005).

Segundo Guareschi e Hilleshein (2007) é necessário que entendamos que a imagem da infância até hoje é narrada por adultos. Já a origem latina da palavra Infância está relacionada à ausência de linguagem. Na história da construção da infância, podemos encontrar a ideia de criança como um ser incompleto, que apenas será concluído quando alcançar a vida adulta (SOUZA, 2016). Destacamos a contradição desse pensamento com a proposta liberal que incentiva a meritocracia e, assim, a ideia de que o sujeito é fruto de seus próprios esforços desde a infância para sua ascensão econômica e social. Lembramos que, em uma sociedade marcada pela desigualdade, que não oferece, através da efetivação de políticas públicas, subsídios para que isso aconteça, essa crença acaba responsabilizando o indivíduo pelo próprio fracasso.

Nesse sentido, entendemos que o ECA vem como uma forma de igualar infâncias desiguais. Não podemos negar que o Estatuto possui vários avanços em relação às políticas sociais antes dele publicadas, como reconhecer crianças e adolescentes como pessoas de direito e substituir o termo menor, na tentativa de descriminalizar a infância pobre. Porém, ele não deixa de ser uma forma compensatória de resolver a dicotomia Infância Normal versus Infância de Risco, reforçando essas diferenças (BRASIL, 1990a; CRUZ; HILLESHEIN; GUARESCHI, 2005).

Instrumentalizar crianças e adolescentes sobre os próprios direitos é uma das maneiras mais efetivas de pôr o Estatuto em prática (VIANA, 2016). É assim, através da produção da autonomia, que políticas públicas como o ECA e o SUS encontraram ferramentas para serem legislações mais funcionais. Destacamos também que, a partir de mecanismos semelhantes aos já discutidos aqui, com a Modernidade também 
foi instituída uma visão de mundo e de sujeito universal, pautada no biologicismo, onde conceitos como saudável e doente tinham apenas uma definição, e tudo o que escapasse dela era patologizado e/ou discriminado, ficando às margens da sociedade.

O conceito de gênero também foi construído em um contexto parecido. Tido como sinônimo de sexo biológico por muito tempo é por nós aqui entendido como um processo, um devir, construído por atos discursivos, sendo algo que fazemos e não algo que somos. O sistema de verdades absolutas que transitam neste campo de saberes é um veículo que oprime certos grupos, o que acontece com mulheres e LGBT (lésbicas, gays, bissexuais, travestis, transexuais e transgêneros), além de outros. A identidade de gênero não é algo que somos totalmente livres para escolher. Podemos apenas interpretar as normas existentes de gênero, as reorganizando. Ou seja, adequamo-nos de uma maneira ou outra dentro das opções que nos são apresentadas desde pequenos. Por outro lado, não negamos a existência de modos de vivenciar o gênero que são subversivos, escapando da esperada normatividade (BUTLER 1987; 2008; SALIH, 2012).

Viana (2016 apud FREIRE, 1981, p. 30) destaca, quando fala sobre a emancipação do sujeito através da educação e da influência dela na construção da infância e do ECA, que não devemos encarar as condições de desigualdades como destino dado, mas sim como resultado de uma configuração social injusta que gera violência e opressão. A importância de o sujeito ter consciência do inacabamento e do não determinismo histórico de sua subjetividade, para poder se libertar das amarras do condicionamento social é, portanto, primordial para reiventarmos práticas em nosso cotidiano.

\section{Método}

A referida pesquisa tem natureza qualitativa, com um delineamento documental. Para a sua realização, foram investigados, nas sessões saúde do jornal Zero Hora do ano de 1990, os sentidos de Gênero, Saúde e Infância ali veiculados. Todo o acervo contendo essas publicações está 
disponível para o público no Museu de Comunicação Hipólito José da Costa, em Porto Alegre, Rio Grande do Sul, local onde foram fotografadas as páginas do jornal que, posteriormente, compuseram o corpus desta investigação.

Para a coleta, adotamos palavras-chave para nos auxiliar nos critérios de inclusão das reportagens, escolhidas a partir dos aportes teóricos usados e do que preconiza o próprio ECA, sendo elas: Família; Criança; Infância; Pré-Natal; Gestação e Bebê. A única exceção, que não está de acordo com o ECA, mas que foi incluída como critério, é a palavra Menor, pois, como já existe uma familiarização das pesquisadoras com os materiais e sendo este um termo muito utilizado quando se fala em infância, entende-se que sua exclusão acarretaria na perda de dados importantes.

Ainda, escolhemos fazer a pesquisa com os meses que antecedem a publicação do ECA. Dessa forma, foram inclusos os meses de janeiro a julho do ano de 1990. A Sessão Saúde dos jornais se divide entre as notícias do dia e a coluna Viva Melhor, onde um profissional da saúde responde perguntas aos/as leitores/as. No domingo, além da Sessão Saúde, também existe a editoria "Ciência e Saúde".

A análise das práticas discursivas para a compreensão dos sentidos cotidianos dados à infância, à família e às questões de gênero no ano de 1990 foi inspirada em autores/as que articulam a análise de discurso com a perspectiva construcionista (SPINK, 2013a; SPINK, 2013 b; SPINK et al., 2014; SPINK et al., 2013).

A seleção e posterior análise do material foi feita, primeiramente, por cada um dos cinco membros do grupo de pesquisa, individualmente. Posteriormente, as seleções foram compartilhadas e, então, em conjunto, selecionados os 33 textos a serem analisados.

Para análise dos materiais elaboramos uma tabela levando em consideração os objetivos que constavam no projeto de pesquisa (Quadro 1). Além de dados de identificação, como título, data e palavra-chave, incluímos nela espaço para identificação de quais discursos de gênero, saúde e infância apareciam na reportagem, quais as (des)articulações 
136 TÍTUlo:

com o SUS e com o ECA e como abordava-se a relação do cuidado e da família.

Quadro 1 - Instrumento para análise do corpus

\begin{tabular}{|l|l|l|l|}
\hline \multicolumn{2}{|l|}{ Título: } \\
\hline Data: & Palavra-chave: & Página: & Editoria: \\
\hline O que fala: & \\
\hline Discursos de gênero/saúde/infância: \\
\hline Articulação com ECA/SUS: \\
\hline Como aborda o cuidado e a família: \\
\hline
\end{tabular}

Fonte: Elaborado pelas autoras (2018)

A construção do instrumento de coleta de dados se deu com base em pressupostos clássicos da Análise de Discurso, tais como atos de linguagem, prática discursiva, enunciador, legitimação discursiva, atos de fala, sentido e texto (IÑIGUEZ et al., 2004) e nas explanações de autores/as da Análise do Discurso e do Construcionismo Social que porpõem a construção de Mapas Dialógicos como forma de elaborar a leitura de um corpus, a partir das perspectivas epistemológicas deste estudo (SPINK et al., 2014).

A elaboração do mapa se dá por intermédio de uma imersão do/a pesquisador/a no documento em análise, a partir de conhecimentos prévios em pressupostos da Análise do Discurso, das visões de sujeito e de mundo que carrega consigo, dos objetivos do estudo e dos processos macropolíticos que transversalizam o material. A partir daí, constrói-se um caminho para a análise, o qual não se tem a pretensão de ser replicado, dentro de um ideal de ciência neutra e objetiva. Contudo, o método é construído com base em conhecimento científico, e a articulação entre teoria, ferramentas de análise, leitura do campo social, articulada ao material e discussão entre os membros do grupo de pesquisa evidenciam a seriedade e minuciosidade da análise.

Spink (2013) destaca o cuidado necessário com a pesquisa com materiais de domínio público, descrevendo a importância de não se adotar 
um pensamento linear ao analisar um contexto histórico, já que a realidade não se faz apenas por acontecimentos e datas, mas também pelo sentido que o sujeito dá aos mesmos. O cotidiano não é algo dado, algo natural na vida do humano, mas sim construído através das significações. Para Hennigen (2006), o sujeito dá sentido ao seu cotidiano através de discursos, que usa para conhecer a si e ao mundo. Nesse processo, toma-os como verdade e, ao se reconhecer neles, (des)constrói o mundo e a si mesmo.

A mídia faz parte desse processo, na medida em que é um dos mais importantes veículos de produção de subjetividade. Também conhecemos o mundo através do que lemos nos jornais e assistimos nas novelas. Apesar de não ser possível uma comunicação com o/a interlocutor/a (no caso da mídia impressa), o sujeito que lê um jornal tem a possibilidade de significar seu conteúdo de diferentes formas. Por isso, destacamos que não somos passivos/as diante das relações midiáticas, sendo sempre possível um movimento de resistência e questionamentos das verdades ali postas (THOMPSON, 2014).

A partir da construção dos quadros, foram elaborados três eixos temáticos, com base nas propostas de Spink et al. (2013). Em meio a eles, escolhemos um para ser apresentado neste artigo. Destacamos que, para facilitar a leitura e compreensão do texto, elegemos uma pequena quantidade de notícias e propagandas para aqui exemplificar o universo em análise, sendo elas as mais representativas para a discussão e que possibilitavam a articulação entre o todo e as partes analisadas.

\section{(In)visibilidades e o discurso biomédico da psicología do desenvolvimento}

Em meio às análises, pudemos constatar que a década de 1990 do século XX é marcada pelo discurso positivista e biologicista, no que tange às práticas de saúde. As questões discutidas na área da infância, em sua grande maioria, falam sobre temas relacionados ao desenvolvimento humano, o que é compreensível, sabendo que analisamos apenas artigos 
relacionados a crianças. Entretanto, perguntamos: quais assuntos são enfatizados pelos/as autores/as dessas reportagens e pelos/as profissionais da saúde que falavam através delas? Quais sentidos sobre os processos vividos pelas crianças foram veiculados nesses jornais? De que crianças estavam falando?

Primeiramente, chamou-nos atenção que boa parte das reportagens falava da primeira infância, mais especificamente dos/as recém-nascidos/as. Sobre a educação e a saúde dessas crianças, o discurso de como cuidar cai em dicotomias muito comuns do biologicismo: saudável versus não saudável, certo versus errado, etc. Na tentativa de classificar e enquadrar sujeitos em discursos e modos de agir, a ciência positivista acabou criando dicotomias como essas, que, ao longo do século XX - e no que já vivemos do XXI - vem excluindo sujeitos que não se encaixam nelas (GERGEN, 2009; BUTLER apud SALIH, 2013).

Nos jornais, o "auxílio" às famílias para cuidarem dos/as filhos/as é extremamente prescritivo, ou seja, mostra-se um jeito "correto" e as consequências caso essas prescrições não sejam seguidas. Em algumas reportagens é possível ver rechaço a novas configurações familiares da época, como ao divórcio e ao distanciamento da família de origem.

Por exemplo, em uma das reportagens, intitulada "Filhos problemáticos: a saída é o psiquiatra” (ZERO HORA, 1990, p. 23) é possível ver algumas dessas questões presentes no discurso do jornal, que veiculou a matéria, e dos/as profissionais que são entrevistados/as e dão informações sobre o assunto. Trata-se de um texto sobre o crescente número de procura por atendimento psiquiátrico infantil e adolescente e sobre a causa de tais atendimentos.

Ao descrever esses fenômenos, o jornal usa repetidamente palavras como doença, distúrbio e problemas (ZERO HORA, 1990, p. 23), descrevendo o que parece ser o desvio de algo que só apresenta duas possibilidades: a norma ou a patologia. Além disso, também é feita uma relação desse aumento na procura por psiquiatras com a educação e com o momento que as crianças da época estavam vivendo. $\mathrm{O}$ jornal, por meio do discurso dos/as profissionais convidados/as a falar, critica as 
novas configurações familiares e a educação que "em nome da liberdade se faz licenciosidade com as crianças" (ZERO HORA, 1990, p. 23).

Há, em meio ao jornal, um rechaço a novos modos de viver, e uma tentativa de adequar as famílias à norma, destacando as consequências caso se opte pelo contrário. Vale destacar que, seguindo a lógica positivista, o jornal autoriza apenas algumas pessoas a falarem sobre esses temas. Dentro da área da saúde, observamos a prevalência do/a pediatra e do/a psiquiatra para falar sobre temas como o desenvolvimento e a relação da criança com os pais. Inclusive, algumas notícias falam sobre eventos voltados para profissionais da área da saúde com palestras ministradas por psiquiatras.

Consequentemente, pela valorização que se deu ao discurso científico (FOUCAULT, 2002), foi enaltecido junto com ele o/a seu/a porta-voz: o/a cientista, o/a expert (BAREMBLIT, 2002), excluindo-se o saber popular e todo o conhecimento gerado pela comunidade.

Colocamos ainda aqui em questão a aplicabilidade dos princípios do ECA em um contexto onde os resquícios de uma ciência dura ainda possui maior status. Acreditamos que a contradição entre a visão de infância encontrada dentro desse eixo em questão, cristalizada e ainda marcada pelo discurso da diferença, vai de encontro ao que preconiza o Estatuto, que pensa na construção da infância como um conceito que vem se modificando ao longo do tempo (CRUZ; HILLESHEIN; GUARESCHI, 2005).

No que diz respeito aos aspectos de gênero, a lógica binária impressa no jornal está retratada no exercício de veiculação de enunciados que tratam de papéis parentais e dos cuidados da criança. Dentro da família, o ZH dá destaque à maternidade e à paternidade por intermédio da (re) produção e/ou demarcação de papéis diferenciados.

A maternidade é extremamente valorizada nas reportagens, na medida em que aparece em boa parte das colunas analisadas. A mãe é trazida como principal agente de cuidado quando se trata da infância e existe um forte apelo emocional envolvido no discurso para manter essa lógica 
de pé. Uma das reportagens assim destaca que "a gestação continua também após o parto” (ZERO HORA, 1990, p. 25).

Uma das estratégias usadas para sustentar esse modo de entender e sentir o mundo veiculado pelo jornal é o uso do discurso biológico. A valorização do leite materno aparece como uma alternativa de colar ainda mais a maternidade a um ato de amor e proteção instintivo. Especialistas da época, que ganhavam espaço nas páginas do jornal, afirmavam os benefícios não só físicos para a criança, mas também sustentavam que o bebê alimentado pelo leite materno recebia não apenas o alimento biológico, mas afetivo necessário ao seu desenvolvimento, e que tais ações estreitavam ainda mais sua conexão com as mães.

Todas essas questões responsabilizavam os cuidados do/a filho/a à mulher já que, naquele cenário, a função materna/paterna estava diretamente ligada ao sexo biológico. Um exemplo disso é uma das reportagens com o título "Mãe e bebê devem ficar sempre juntos" (ZERO HORA, 1990, p. 25), onde é transmitida a ideia de que a mãe é a responsável pela saúde física e emocional da criança. A coluna fala também sobre o/a recém-nascido/a não ter tanta autonomia, possuir necessidades que apenas a mãe pode prover e que sua comunicação está basicamente voltada a ela.

Badinter (1985) afirma que a maternidade nem sempre foi entendida e investida da mesma forma e que, para entendê-la enquanto um fenômeno inventado e diretamente ligado ao contexto em que é narrada, é preciso recorrer à História. A prática da amamentação por amas de leite, comum nos séculos passados, é um dos exemplos que põem em xeque o amor materno como sendo uma característica biológica e inata de todas as mães. As péssimas condições de saúde e higiene que demonstravam um investimento quase nulo na infância dos séculos XVI e XVII nos leva a destacar o quanto conceitos como Maternidade e Infância vêm se modificando ao longo do tempo.

A própria coluna Viva Melhor, onde, por algumas vezes apareceram perguntas ao colunista questionando sobre hábitos de cuidado com as crianças, é uma das provas de que não existe uma única atitude materna, 
e o próprio jornal é registro deste fato. O que existe são várias formas de se expressar o cuidado e discursos autorizados pela ciência proferidos por especialistas que procuram padronizar essas diferentes manifestações da maternidade. Na tentativa de reconhecer essas diferentes manifestações, a ciência faz um movimento parecido com o que já discutimos acima com as dicotomias, e esses modos de cuidado são classificados em grupos, ditos “normais” ou "de risco" (STREY; CADONÁ, 2012).

Em meio a tais argumentações, uma das figuras de cuidado na vida da criança acaba ficando apagada. A paternidade, nas reportagens que foram analisadas, pouco apareceu. Os pais surgem algumas vezes citados como dupla parental quando se fala na educação de crianças mais velhas, e não recém-nascidas. Nas reportagens o jornal fala sobre gravidez e acompanhamento durante esse período e, mesmo assim, o papel do pai não é destacado.

Saldanha, Muhlen e Strey (2012) apontam que os avanços no mundo contemporâneo, com o declínio do patriarcado, principalmente impulsionado pelos movimentos feministas, vêm causando mudanças no cenário da família moderna. Em ritmo diferente da maternidade, o conceito de paternidade também sofre mudanças, assim como o papel que o homem ocupa na sociedade.

Apesar dessas mudanças, a referência de família encontrada nos jornais ainda é de marido, mulher e filhos/as, a mesma que ainda predomina nas sociedades ocidentais contemporâneas. Marcondes (2012) discute sobre como as relações sociais que originaram esse modelo de família surgiram de uma divisão dicotômica de gênero entre a esfera pública e privada. A esfera privada era atribuída socialmente à mulher, que ficaria com o cuidado dos/as filhos/as e com a organização doméstica. Já na esfera pública, a responsabilidade por sua manutenção seria do homem, que exerceria autoridade sobre a mulher, provendo a família, e exercendo atividades sociais, como o trabalho. Esse é um modelo pautado na assimetria de gênero, onde o masculino exerce predomínio sobre o feminino, e que deixou marcas nas relações sociais que podem ser vistas até hoje. 
As reportagens analisadas refletem essa disparidade nas relações de gênero pautadas na diferença. Ao homem não eram atribuídos os cuidados com o/a filho/a, não havendo um apelo da ciência para fortalecer um sentimento de instinto paterno, já que o mesmo nunca fez parte da história da paternidade. O pai aparece em algumas reportagens relacionadas a crianças mais velhas, já em idade escolar, quando sua autoridade pode ser reivindicada na educação dessa criança.

No caso do ECA, acerca da questão da responsabilidade para com a criança, em nenhum momento se ressalta que os cuidados devam ser de exclusividade da mãe, ou se dá algum tipo de distinção de gênero quanto a isso (BRASIL, 1990a). No entanto, isso não garante que essa disparidade não aconteça na aplicabilidade da Lei. Será possível pôr em prática o Estatuto com uma forte produção de subjetividade trabalhando no sentido de reforçar cada vez mais a magnitude da maternidade e a invisibilidade da paternidade?

\section{Conclusão}

O fim da década de 1980 e o início da década de 1990 têm como característica um marco no que diz respeito à aprovação de políticas públicas. Além da Constituição Federal (BRASIL, 1988) e das Leis Federais trabalhadas neste artigo, SUS e ECA, em 1993 é aprovada a Lei Orgânica da Assistência Social (BRASIL, 1993). Todas essas legislações têm em comum uma ruptura com visões de mundo e de sujeito de publicações que as antecediam. Nossa pesquisa se preocupou em se questionar e responder, dentre outras, a pergunta: é possível pôr em prática os princípios do ECA e do SUS em meio às publicações midiáticas da época?

Devemos destacar que a conjuntura midiática é apenas um recorte da realidade que vivia a população de 1990, portanto, nossa análise não apresenta uma verdade única sobre o contexto da época. Não é nossa intenção fechar a discussão, ou esgotá-la com os materiais de análise, mas sim abrir a reflexão para uma realidade complexa que interfere até hoje no modo como duas importantes políticas públicas são postas em práticas em nosso País. 
Sabemos, como já discutimos antes, que a melhor forma de aplicar políticas como o ECA e o SUS é através da instrumentalização do público. É na autonomia que tais legislações encontram forças (VIANA, 2016). Nas reportagens analisadas, principalmente nas que dizem respeito ao modo como o Estado lida com a saúde na infância, encontramos um modo autoritário de intervenções, fugindo bastante do que preconizam as duas legislações estudadas.

A própria ênfase em um discurso biologicista, que autoriza apenas o profissional da medicina a falar sobre as questões do desenvolvimento infantil, como um expert, coloca em xeque os princípios e diretrizes do SUS. Sabemos que o mesmo preconiza o trabalho multidisciplinar, onde o/a próprio/a usuário/a é considerado/a o/a maior conhecedor/a do que está passando, e, portanto, as informações não são dadas de maneira prescritiva, como vimos nos jornais.

Em relação às questões de gênero, conseguimos visualizar uma disparidade no que diz respeito à visibilidade dos papéis da maternidade e da paternidade. Embora a sociedade venha evoluindo, ainda dicotomizados e cristalizados, esses papéis refletem uma realidade onde mães ainda são vistas como as principais cuidadoras dos filhos, enquanto os pais são responsáveis por prover o sustento da casa.

Guattari e Rolnik (1996) destacam a importância da análise da produção de subjetividade usando o exemplo de que quando uma potência, como os Estados Unidos da América, quer implantar algum tipo de possibilidade de expansão econômica em um País de terceiro mundo, ela começará trabalhando os processos de subjetivação. Podemos trazer isso para a pesquisa pensando que para que as políticas públicas fossem implantadas com sucesso uma das maneiras de trabalhar a produção de subjetividade na época era através da mídia impressa, que como verificamos ia de encontro, na maioria das vezes, com o que as mesmas preconizavam.

Para concluir, fazemos uma reflexão sobre o processo de pesquisa e seu fim, com o sentimento de que ele não deve terminar por aqui. Muitas vezes, dentro do universo da pesquisa, nos deparamos com barreiras 
e práticas que vão contra nossa visão de mundo, e que nos levam a sentimentos de frustração. Infelizmente, muitas pesquisas acabam ficando apenas no papel e não cumprem com seus objetivos, nunca retornando a quem lhes pertence: a comunidade.

Acreditamos que a pesquisa não deve ter um fim nela mesma. Nossos resultados devem ser incorporados a nossas práticas, debatidos com profissionais das áreas interessadas, e, por que não, usados como justificativas para bons projetos de extensão? Por exemplo, um dos modos de levar a pesquisa para fora da universidade seria transformá-la em um programa de extensão para discutir com os/as profissionais da área da saúde sobre as origens do SUS e as repercussões até hoje em suas práticas. Dessa forma, a pesquisa cumpre seu papel de transformadora da realidade.

"Se podes olhar, vê. Se podes ver, repara", disse José Saramago (1997, p. 9) em Ensaio sobre a cegueira. Em outras palavras, temos as ferramentas para mudar a realidade em que vivemos, e agora precisamos usá-las com mais inteligência. De modo contrário, continuaremos vendo sem reparar.

\section{Referências}

ARIÈS, P. História social da criança e da família. 2. ed. Rio de Janeiro: LTC, 1981. BADINTER, E. Um amor conquistado: o mito do amor materno. Rio de Janeiro: Nova Fronteira, 1985.

BAREMBLITT, G. Compêndio de análise institucional e outras correntes: teoria e prática. 5. ed. Belo Horizonte: Instituto Felix Guattari, 2002.

BRASIL. Constituição Federal de 1988. Disponível em: http:/www.planalto.gov.br/ccivil_03/constituicao/constituicao.htm. Acesso em: 23 set. 2019.

Lei n. 8.069, de 13 de julho de 1990a. Dispõe sobre o Estatuto da Criança e do Adolescente e dá outras providências. Disponível em: http://www.planalto.gov.br/ ccivil_03/leis/L8069Compilado.htm. Acesso em: 23 set. 2019.

Lei n. 8.080, de 19 de setembro de 1990b. Dispõe sobre as condições para a promoção, proteção e recuperação da saúde, a organização e o funcionamento dos serviços correspondentes e dá outras providências. Disponível em: http://www.planalto.gov.br/ ccivil_03/leis/18080.htm. Acesso em: 23 set. 2019. 
Lei n. 8.142, de 28 de dezembro de 1990c. Dispõe sobre a participação da comunidade na gestão do Sistema Único de Saúde (SUS) e sobre as transferências intergovernamentais de recursos financeiros na área da saúde e dá outras providências. Disponível em: http://www.planalto.gov.br/ccivil_03/leis/18142.htm. Acesso em: 23 set. 2019.

Lei n. 8.742, de 07 de setembro de 1993. Dispõe sobre a organização da Assistência Social e dá outras providências. Disponível em; http://www.planalto.gov.br/ ccivil_03/leis/L8742compilado.htm. Acesso em: 23 set. 2019.

BUENO, E. Brasil: uma história: cinco anos de um país em construção. Rio de Janeiro: Leya, 2012.

BUTLER, J. Variações sobre sexo e gênero: Beauvoir, Wittig e Foucault. In: BENHABIB, S.; Cornell, D. (coord.). Feminismo como crítica da modernidade. Rio de Janeiro: Rosa dos Tempos, 1987.

BUTLER, J. Problemas de gênero: feminismo e subversão da identidade. Rio de Janeiro: Civilização Brasileira, 2008.

CADONÁ, E. et al. Conceitos de saúde e cuidado na mídia impressa brasileira: uma análise do ano de 1990. Curitiba: CRV, 2017.

CAMPOS, G.; CAMPOS, R. Co-construção de autonomia: o sujeito em questão. In: . Tratado de saúde coletiva. São Paulo: Hucitec, 2012.

CRUZ, L.; HILLESHEIN, B.; GUARESCHI, N. M. F. Infância e políticas públicas: um olhar sobre as práticas psi. Psicologia ๒ Sociedade, Porto Alegre, v. 17, n. 3, p. 42-49, set.-dez. 2005.

FOUCAULT, M. Microfisica do poder. 17. ed. Rio de Janeiro: Edições Graal, 2002.

GERGEN, K. J. O movimento do construcionismo social na psicologia moderna. Revista Internacional Interdisciplinar INTERthesis, Florianópolis, v. 6, n. 1, p. 299-325, jan.-jul. 2009.

GUARESCHI, P. Psicologia social crítica: como prática de libertação. Porto Alegre: EDIPUCRS, 2004.

GUATTTARI, F.; ROLNIK, S. Micropolítica: cartografias do desejo. 4. ed. Petrópolis: Vozes, 1996.

HENNIGEN, I. Subjetivação como produção cultural: fazendo uma outra psicologia. Psicologia ๒ Sociedade, Porto Alegre, v. 18, p. 47-53, maio-ago., 2006.

HILLESHEIN, B.; GUARESCHI, N. M. F. De que infância nos fala a psicologia do desenvolvimento? Algumas reflexões. Psicologia da educação, São Paulo, v. 25, p. 75-92, 2. sem. 2007.

IÑIGUEZ, L. et al. Manual de análise de discurso em ciências sociais. Petrópolis: Vozes, 2014.

INIGUEZ, L. A Pós-modernidade: O novo Zeitgeist de Nosso Tempo. In: MARTINS, J. B. (Org.). Temas em análise institucional e em construcionismo social. São Carlos: Fundação Araucária, 2002. 
LARA, L. Saúde pública e saúde coletiva: investindo na infância para produção de cidadania. 2009. 81f. Tese (Doutorado em Programa de Pós-Graduação em Psicologia). Porto Alegre: Pontifícia Universidade Católica do Rio Grande do Sul, 2009.

LOURO, G. L. Gênero, sexualidade e educação: uma perspectiva pós-estruturalista. 6. ed. Petrópolis: Vozes, 2003.

MARCONDES, G. S. As trajetórias dos homens de família: os significados da vida conjugal e parental masculina. In: STREY, M. N. et al. (Orgs.). Gênero e ciclos vitais: desafios, problematizações e perspectivas. Porto Alegre: Edipucrs, 2012.

PADRÓS, E. S. Os desafios na produção do conhecimento histórico sob a perspectiva do Tempo Presente. Anos 90, v. 11, n. 19/20, jan.-dez., 2004.

RODRIGUES, M. A década de 80: Brasil: quando a multidão voltou às praças. São Paulo: Ática, 1992.

SALDANHA, M.; MUHLEN, B. K. Von; STREY, M. O homem maternante: mudanças à vista? In: STREY, M. N. et al. (Orgs.). Gênero e ciclos vitais: desafios, problematizações e perspectivas. Porto Alegre: Edipucrs, 2012.

SALIH, S. Judith Butler e a teoria queer. 1. ed. Belo Horizonte: Autêntica Editora, 2013. SARAMAGO, J. Ensaio sobre a cegueira. São Paulo: Companhia das Letras, 1995.

SOUZA, M. A. 25 anos do Estatuto da Criança e do Adolescente: História, política e sociedade. In: CONSELHO FEDERAL DE PSICOLOGIA. MOREIRA, J. O.; SALUM, M. J. G.; OLIVEIRA, R. T. (Orgs.). Estatuto da criança e do adolescente: refletindo sobre sujeitos, direitos e responsabilidades. Brasília: CFP, 2016.

SPINK, M. J.; SPINK, P. Introdução. In: MEDRADO, M.; PASSARELLI, C.; LIMA, H.; MIRIAM, L.; SPINK, M.; FREZZA, R.; MENEGON, V. Práticas cotidianas e a naturalização da desigualdade. São Paulo: Cortez, 2006.

SPINK, M. J. et al. Práticas discursivas e produção de sentidos no cotidiano. Rio de Janeiro: Cortez, 2013a.

SPINK, P. Análise de documento de domínio público. In: SPINK, M. J. (Org.). Práticas discursivas e produção de sentidos no cotidiano. Rio de Janeiro: Cortez, 2013b.

SPINK et al. A produção de informação na pesquisa social: compartilhando ferramentas. Rio de Janeiro: Centro Edelstein de Pesquisas Sociais, 2014.

STREY, M. N.; CADONÁ, E. A construção do sujeito materno: problematizando práticas à luz dos estudos feministas. In: STREY, M. N. et al. (Orgs.). Gênero e ciclos vitais: desafios, problematizações e perspectivas. Porto Alegre: Edipucrs, 2012.

THOMPSON, J. B. A mídia e a modernidade: uma teoria social da mídia. Petrópolis: Vozes, 2014.

VIANA, M. A psicologia escolar, o ECA e o enfrentamento à teoria do capital humano. In: CONSELHO FEDERAL DE PSICOLOGIA. MOREIRA, J. O.; SALUM, M. J. G.; OLIVEIRA, R. T. (Orgs.). Estatuto da criança e do adolescente: refletindo sobre sujeitos, direitos e responsabilidades. Brasília: CFP, 2016.

ZERO HORA. Coleção de publicações do ano de 1990. Porto Alegre: Zero Hora, 1990. 


\section{Sobre as autoras}

Heloísa Derkoski Dalla Nora - Graduada em Psicologia pela Universidade Regional Integrada do Alto Uruguai e das Missões - Campus de Frederico Westphalen (URI-FW). Pós-Graduanda em Terapia Familiar Sistêmica pela Universidade do Oeste de Santa Catarina (UNOESC - Chapecó). Fez parte do Grupo de Pesquisa em Psicologia da URI-FW, atuando na linha de pesquisa em Políticas Públicas, Saúde e Produção de Subjetividade em Contextos Institucionais, sendo bolsista do projeto de pesquisa intitulado \&quot;Sentidos de Gênero e Saúde no Cenário de Publicação das Leis n. 8.080 e n. 8.142: Uma Análise da Sessão Saúde do Zero Hora. No presente artigo, a autora participou da concepção do desenho da pesquisa, do desenvolvimento da discussão teórica, da coleta e interpretação dos dados, da redação do manuscrito e da revisão do texto.

Eliane Cadoná - Doutora em Psicologia (PUCRS). Mestre em Psicologia Social (PUCRS). Especialista em Psicologia Clínica Ampliada e graduada em Psicologia e em Ciências Biológicas (URI - Campus de Frederico Westphalen). Professora da URI/FW e atual Coordenadora do Curso de Psicologia desta mesma Universidade. Professora do Programa de Pós-Graduação - stricto sensu - em Educação URI/FW, atuando na linha de pesquisa Processos Educativos, Linguagens e Tecnologias. Líder e integrante do Grupo de Pesquisa em Psicologia da URI - Campus de Frederico Westphalen, com pesquisa no âmbito das Políticas Públicas, Saúde e Produção de Subjetividade em Contextos Institucionais. No presente artigo, a autora participou da concepção do desenho da pesquisa, na condição de orientadora da pesquisa, do desenvolvimento da discussão teórica, da coleta e interpretação dos dados, da redação do manuscrito e da revisão do texto.

Data de submissão: 25/09/2019

Data de aceite: 24/01/2020 